\title{
Electrodeposition of Nickel-Phosphorus Alloy from Sulfamate Baths with Improved Current Efficiency
}

\author{
C. S. Lin, ${ }^{\mathrm{a}, *, \mathrm{z}}$ C. Y. Lee, ${ }^{\mathrm{b}}$ F. J. Chen, ${ }^{\mathrm{a}}$ C. T. Chien, ${ }^{\mathrm{a}}$ P. L. Lin, ${ }^{\mathrm{a}}$ and W. C. Chung ${ }^{\mathrm{a}}$ \\ ${ }^{a}$ Department of Materials Science and Engineering, National Taiwan University, Taipei 106, Taiwan \\ ${ }^{b}$ Department of Mechanical and Automation Engineering, Da-Yeh University, Da-Tsuen, Changhua 515, \\ Taiwan
}

In this study, nickel-phosphorus (Ni-P) deposits were electroplated from the nickel sulfamate bath containing phosphorous acid using a pulse current, with emphasis on the effect of current density, duty cycle, and frequency of the pulse current. Experimental results show that both the deposit phosphorus content and current efficiency were substantially enhanced by employing the pulse current, preferentially at low duty cycles. The underlying difference for the dc and pulse currents on the effect of deposit phosphorus content and current efficiency can be explained by the detailed half-reactions relevant to incorporation of phosphorus into $\mathrm{Ni}-\mathrm{P}$ alloys. Less variation in surface proton, $\mathrm{Ni}^{2+}$ and $\mathrm{H}_{3} \mathrm{PO}_{3}$ concentration due to the diffusion recovery during the time off of a pulse current is believed to play an important role in the improvement of the plating process.

(C) 2006 The Electrochemical Society. [DOI: 10.1149/1.2186798] All rights reserved.

Manuscript submitted September 9, 2005; revised manuscript received January 27, 2006. Available electronically April 6, 2006.

Nickel-phosphorus (Ni-P) alloys have been extensively used as protective coatings ${ }^{1-4}$ or electrodes for electrochemical catalysis, ${ }^{4-10}$ in which the alloys are generally fabricated by electroless plating or electrodeposition. The latter have many advantages over the former, such as the higher deposition rate in a simpler electrolyte and the feasibility to tailor the deposit composition and microstructure by varying the applied current waveform.

$\mathrm{Ni}-\mathrm{P}$ electrodeposition is usually performed in the solution made up of $\mathrm{Ni}^{2+}$ ions and phosphorus oxyacid, which once reduced provides the source of phosphorus in the deposit. Phosphorus deposit, however, cannot be achieved in the solution consisting solely of phosphorus oxyacid, leading to the emergence of two codeposition mechanisms for Ni-P electrodeposition: direct mechanism and indirect mechanism. Some researchers, first Brenner ${ }^{11}$ and recently Morikawa et al., ${ }^{12}$ considered the direct codeposition mechanism as that where $\mathrm{Ni}^{2+}$ and phosphorus oxyacid are directly reduced to nickel and phosphorus adatoms, which then combine to form $\mathrm{Ni}_{n} \mathrm{P}$ solid solution. ${ }^{4,12}$ For indirect codeposition mechanism, phosphorus oxyacid is reduced to phosphine which then, in the presence of $\mathrm{Ni}^{2+}$, is oxidized to phosphorus adatoms, while $\mathrm{Ni}^{2+}$ is simultaneously reduced to nickel. ${ }^{1,4,13-17}$ The properties of $\mathrm{Ni}-\mathrm{P}$ electrodeposits can be best related to the phosphorus content and microstructure of the deposit; in particular, the deposits evolve gradually from crystalline to amorphous as their deposit phosphorus content increases. ${ }^{18-20}$ The control in deposit phosphorus content is, therefore, of great importance. In a modified Watts nickel bath containing sodium hypophosphite as a phosphorus source, the phosphorus content of $\mathrm{Ni}-\mathrm{P}$ deposits can be well controlled by the electroplating parameters, specifically the solution temperature and current density of the dc current. $^{21}$ However, the effect of plating parameters on the current efficiency was not reported in Ref. 21. The phosphorus content of the deposit can be increased at the expense of current efficiency by increasing phosphorus oxyacid concentration in the solution. ${ }^{22-25}$ This decrease implies that more charge is consumed for reduction of protons. Proton discharge can cause failure in electroforming or impose adverse effects on deposit properties such as pinholes and residual stress. ${ }^{22,23}$

Pure Ni deposits plated from nickel sulfamate bath generally exhibit lower internal stress than those from sulfate or chloride baths. ${ }^{26-28}$ However, Ni-P electrodeposits plated from the nickel sulfamate bath are less well studied compared with the sulfate and citrate baths. Although dc plating is capable of preparing the Ni-P deposits with various phosphorus contents, the high phosphorus content deposits are generally plated with low current efficiency. ${ }^{22-25}$ In this study, $\mathrm{Ni}-\mathrm{P}$ deposits were electroplated from nickel sulfamate

\footnotetext{
* Electrochemical Society Active Member

${ }^{\mathrm{z}}$ E-mail: csclin@ntu.edu.tw
}

baths containing phosphorous acid using the pulse current. Compared with dc plating, the current efficiency associated with high phosphorus content deposits can be improved by using the pulse current with low duty cycle, high frequency, and proper peak current density.

\section{Experimental}

Electroplating.- Ni-P electrodeposition was performed in the nickel sulfamate bath composed of $90 \mathrm{~g} \mathrm{dm}^{-3} \mathrm{Ni}^{2+}$ (added as nickel sulfamate), $10 \mathrm{~g} \mathrm{dm}^{-3} \mathrm{H}_{3} \mathrm{PO}_{3}, 3 \mathrm{~g} \mathrm{dm}^{-3}$ nickel chloride, $40 \mathrm{~g} \mathrm{dm}^{-3}$ boric acid, and $0.4 \mathrm{~g} \mathrm{dm}^{-3}$ sodium dodecyl sulfate as a wetting agent. The $\mathrm{pH}$ of the solution was approximately 1.5 . To explore the effect of solution $\mathrm{pH}$ on the deposition behavior, the solutions with $\mathrm{pH}$ ranging from 1.0 to 2.5 were prepared by the addition of dilute sulfuric acid or sodium hydroxide. Copper plates and nickel disks were employed as the cathode and anode, respectively. The copper plates were mechanically polished using $\mathrm{SiC}$ abrasive paper to grade 2400 , rinsed with deionized water, cleaned in acetone ultrasonically, and finally dried using a stream of hot air. Prior to electroplating, the plates were cleaned with $5 \%$ sulfuric acid, and subsequently rinsed with deionized water at room temperature. A $2.5 \mathrm{dm}^{3}$ solution at $50^{\circ} \mathrm{C}$ was used for electroplating and was continuously stirred by a stream of room temperature air throughout the electroplating. The electroplating was performed using the pulse current whose peak current density, unless otherwise specified, was $80 \mathrm{~mA} \mathrm{~cm}$. The frequency of the pulse current was varied between 10 and $500 \mathrm{~Hz}$ and the duty cycle (the fraction of time on to the period of a pulse cycle) was set to be 0.5 and 0.1 . Herein, the peak current density, average current density, frequency, and duty cycle of a pulse current were denoted as $I_{\mathrm{p}}, I_{\mathrm{m}}, f$, and $\varepsilon$, respectively, where $I_{\mathrm{m}}=I_{\mathrm{p}} \varepsilon$. The copper plates before and after electroplating were weighted, respectively, using an electronic balance with an accuracy of $0.1 \mathrm{mg}$. The mass of the deposit was the mass difference of the copper plate with and without the deposit.

Microstructural characterization.- The composition of the deposits was measured by electron microprobe analysis (EPMA) and reported as an average of five measurements. Once the composition and mass of the deposit plated with a given charge were known, the current efficiency could be calculated on the assumption that reduction of one $\mathrm{Ni}^{2+}$ and $\mathrm{H}_{3} \mathrm{PO}_{3}$ to nickel and phosphorus involves the transfer of two and three electrons, respectively. Detailed microstructure of the deposits was investigated by cross-sectional transmission electron microscopy (TEM) on the specimens prepared by a combined mechanical grinding and ion-beam thinning technique. The composition of the deposit was also measured via electron energy dispersive spectroscopy (EDS) equipped in TEM as a supplement of the EPMA measurement. Both EDS and EPMA results were 


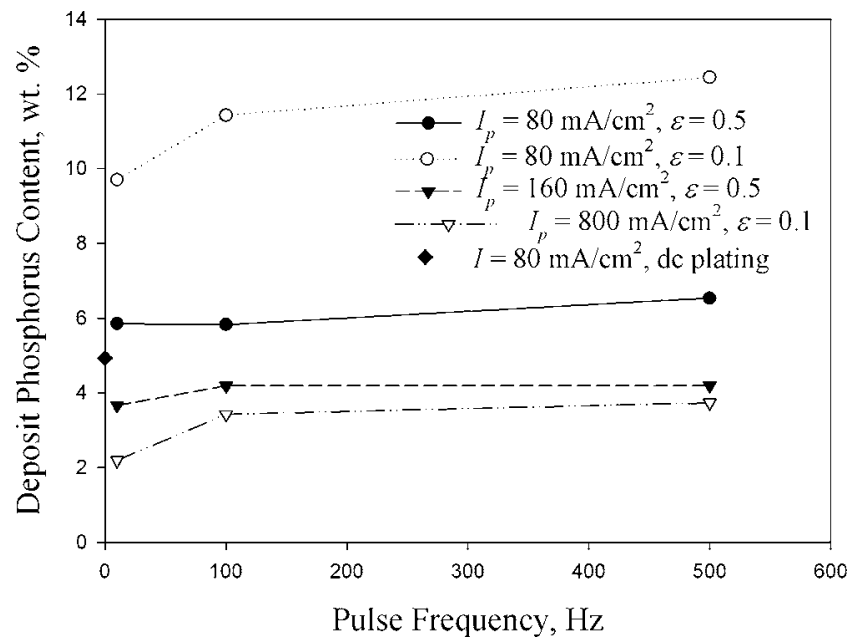

Figure 1. Deposit phosphorus content as a function of the peak current density, pulse frequency, and duty cycle.

quantified using internal standards associated with the equipment. The structure of the deposit was characterized via the selected-area electron diffraction (SAED) technique.

\section{Results}

Composition and current efficiency of the deposits.- Figure 1 shows the deposit phosphorus content as a function of pulse frequency and duty cycle. The data of dc electroplating are also included for comparison. ${ }^{22}$ For the pulse current with $I_{\mathrm{p}}$ equal to the current density of the dc current (both are equal to $80 \mathrm{~mA} \mathrm{~cm}^{-2}$ ), the pulse-plated deposit generally had a higher phosphorus content than the dc-plated counterpart. In contrast, the dc-plated deposit contained more phosphorus than the pulse-plated deposit when $I_{\mathrm{m}}$ of the pulse current was $80 \mathrm{~mA} \mathrm{~cm}{ }^{-2}\left(I_{\mathrm{p}}=160\right.$ and $800 \mathrm{~mA} \mathrm{~cm}^{-2}$ for the current with $\varepsilon=0.5$ and 0.1 , respectively). Furthermore, for the pulse currents with $I_{\mathrm{m}}=80 \mathrm{~mA} \mathrm{~cm}{ }^{-2}$, the deposit phosphorus content decreased with increasing $I_{\mathrm{p}}$ or decreasing $\varepsilon$. Researchers studying $\mathrm{Ni}-\mathrm{P}$ electrodeposition using the dc current also demonstrated that less phosphorus is incorporated into the deposit with increasing current density. ${ }^{22-25}$

Figure 1 also shows that for the pulse currents with $I_{\mathrm{p}}=80 \mathrm{~mA} \mathrm{~cm}^{-2}$, the deposit phosphorus content increased with increasing pulse frequency and reached a constant when the frequency exceeded 10 and $100 \mathrm{~Hz}$ for the waveform with 0.5 and 0.1 duty cycles, respectively. Furthermore, the deposit plated at 0.1 duty cycle had higher phosphorus content than that plated at 0.5 duty cycle regardless of the pulse frequency. It has been previously published that in the bath composed of nickel sulfate and chloride, as well as phosphorus and phosphoric acid, the pulse-plated Ni-P deposit contains more phosphorus than its dc-plated counterpart, ${ }^{1}$ while the deposit phosphorus content is not significantly influenced by the off time at a fixed on time of $2 \mathrm{~ms}^{29}$

Concurrent with the increase in the deposit phosphorus content, the current efficiency decreased as the current waveform was changed from dc to pulse, especially for the current with low frequencies and high peak current densities (Fig. 2). For the pulse currents with $I_{\mathrm{p}}=80 \mathrm{~mA} \mathrm{~cm}{ }^{-2}$, the current efficiency increased with increasing pulse frequency for the waveform with 0.5 duty cycle, while that for the waveform with 0.1 duty cycle hardly changed with the pulse frequency. Moreover, the current efficiency increased as the duty cycle was reduced from 0.5 to 0.1 even though the deposit plated at 0.1 duty cycle contained more phosphorus than that plated at 0.5 duty cycle. Figure 2 also shows that the difference in current efficiency between the waveform with 0.5 and 0.1 duty cycles decreased with increasing pulse frequency.

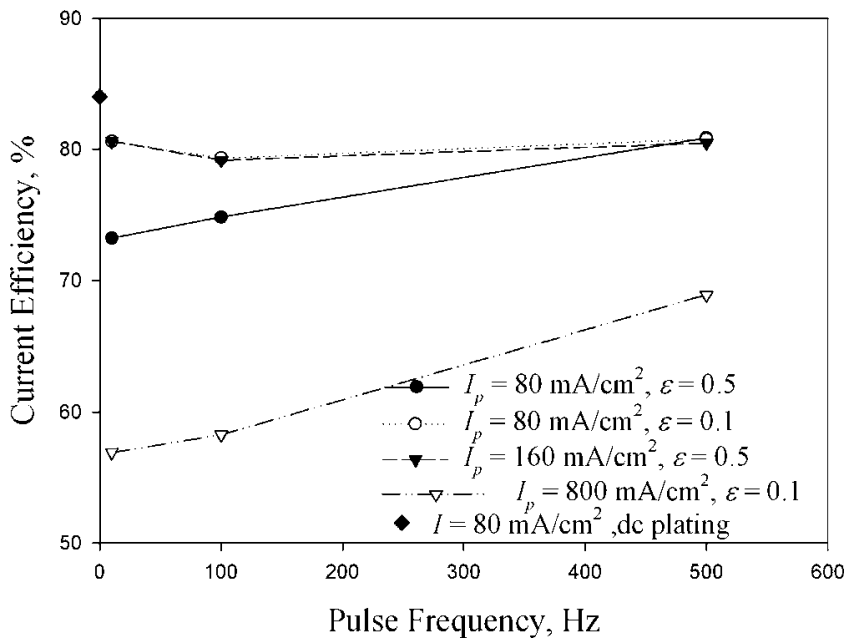

Figure 2. Current efficiency as a function of the peak current density, pulse frequency, and duty cycle.

For the pulse currents with $I_{\mathrm{m}}=80 \mathrm{~mA} \mathrm{~cm}^{-2}$, the current efficiency of the pulse-plated deposit was lower than that of dc-plated deposit regardless of the pulse frequency. Furthermore, the current efficiency decreased markedly as $I_{\mathrm{p}}$ was increased from 160 to $800 \mathrm{~mA} \mathrm{~cm}^{-2}$. When $I_{\mathrm{m}}=80 \mathrm{~mA} \mathrm{~cm}{ }^{-2}$, the deposit was plated with less phosphorus at lower current efficiency compared with the dc-plated counterpart, as shown in Fig. 1 and 2. For example, the deposit plated using the pulse current with $I_{\mathrm{p}}=800 \mathrm{~mA} \mathrm{~cm}{ }^{-2}$ contained less than $3 \mathrm{wt} \%$ phosphorus, meanwhile the current efficiency was below $70 \%$. This is because $800 \mathrm{~mA} \mathrm{~cm}^{-2}$ is well above the limited current density of the typical nickel sulfamate bath. $^{28}$ For the pulse current with $I_{\mathrm{p}}=160 \mathrm{~mA} \mathrm{~cm}{ }^{-2}$, the deposit only contained $4 \mathrm{wt} \%$ phosphorus, although it was plated with the efficiency of around $80 \%$. Therefore, it is likely that the pulse current with $I_{\mathrm{m}}=80 \mathrm{~mA} \mathrm{~cm}-2$ and $\varepsilon$ $\leqslant 0.5$ is not suitable for plating high phosphorus content deposits while maintaining a relatively high current efficiency. Therefore, the following is reported on the basis that both $I_{\mathrm{p}}$ of the pulse current and the current density of the dc current are equal to $80 \mathrm{~mA} \mathrm{~cm}$.

Figure 3 shows the current efficiency versus the deposit phosphorus content for dc-plated and pulse-plated deposits. For dc plating, the current efficiency was relatively high $(>90 \%)$ for the deposits containing phosphorus less than 3 wt \%. A more significant decrease in the current efficiency was observed when the deposit's phosphorus content exceeded 3 wt $\%$. Thereafter, the current efficiency decreased monotonously with the deposit phosphorus content, in which the current efficiency can be as low as $30 \%$ for the deposit having approximately $14 \mathrm{wt} \%$ phosphorus. ${ }^{22}$ The current efficiency of the Ni-P deposit plated from the nickel sulfate bath has been shown to decrease with increasing $\mathrm{H}_{3} \mathrm{PO}_{3}$ concentration, ${ }^{23-25}$ while that plated from the nickel citrate has a maximum current efficiency in the presence of intermediate amounts of $\mathrm{H}_{3} \mathrm{PO}_{3}{ }^{12}{ }^{12} \mathrm{In}$ contrast, the current efficiency associated with pulse plating hardly changed with the deposit phosphorus content, giving rise to higher current efficiencies than the dc-plated counterpart for the deposit with phosphorus content exceeding 6 wt \% (Fig. 3). Moreover, the difference in current efficiency between dc and pulse plating became more pronounced as the deposit phosphorus content was increased.

Microstructure characterization.- Figure 4a shows the crosssectional TEM micrograph of the deposit plated using the $10 \mathrm{~Hz}$ pulse current with 0.5 duty cycle. This deposit, containing approximately $6 \mathrm{wt} \%$ phosphorus, was composed of equiaxed grains because all grains observed in TEM seemed to exhibit a round shape. The size of these equiaxed grains ranged from a few nanometers to $20 \mathrm{~nm}$; accordingly, the SAED pattern (inset in Fig. 4a) consisted of 


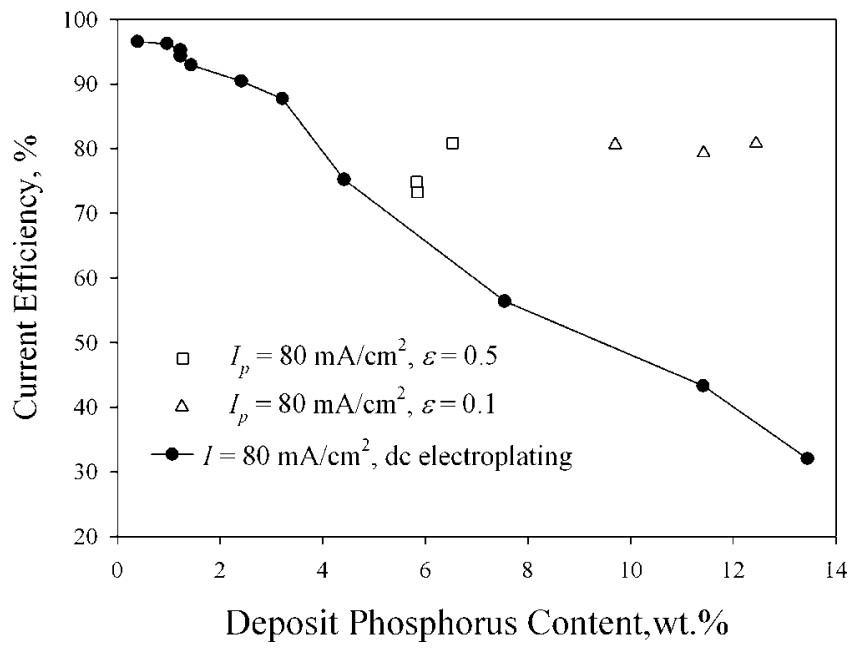

Figure 3. Dependence of current efficiency on the deposit phosphorus content.

continuous rings that can be assigned as the diffractions from nickel. Reducing the duty cycle from 0.5 to 0.1 resulted in the deposit containing around $10 \mathrm{wt} \%$ phosphorus (Fig. 1). The grain size of the deposit was, however, larger than that plated at 0.5 duty cycle, as shown in Fig. 4b. Figure 4c shows the micrograph of the deposit plated using the $100 \mathrm{~Hz}$ pulse current with 0.1 duty cycle. This deposit, having around $12 \mathrm{wt} \%$ phosphorus, also comprised equiaxed grains 30 to $60 \mathrm{~nm}$ in size. The spots in the inset SAED pattern apparently resulted from the diffractions associated with the relatively large grains. A Ni-12 wt. \% P deposit had been made previously in the nickel sulfamate bath containing $30 \mathrm{~g} \mathrm{dm}^{-3} \mathrm{H}_{3} \mathrm{PO}_{3}$ using the dc current and comprised grains several nanometers in size (Fig. 5c in Ref. 22). Pulse plating apparently resulted in the deposits with higher phosphorus contents and a larger grain size. This is different from the dependence of grain size on the phosphorus content of dc-plated deposits, in which the grain size decreases with increasing deposit phosphorus content and the deposit would become amorphous as the deposit phosphorus content exceeds a critical amount. ${ }^{18-20,22}$

\section{Discussion}

Deposit phosphorus content.-Compared with de plating, pulse plating can plate $\mathrm{Ni}-\mathrm{P}$ electrodeposits with higher phosphorus content at larger current efficiency, particularly for the pulse currents with $I_{\mathrm{p}}$ less than the limited current density associated with dc plating. It is not immediately clear as to why the pulse current promotes the codeposition of phosphorus while maintaining a high current efficiency. However, detailed half-reactions relevant to incorporation of phosphorus into Ni-P alloys, which have been uncovered in the literature, ${ }^{1,4,12-15,17}$ can be the basis for understanding the effect of pulse current on the deposit phosphorus content and current efficiency.

According to the half-reactions, $\mathrm{Ni}^{2+}$ and protons can be reduced directly on the cathode (Reactions 1 and 2) in the nickel sulfamate bath containing $\mathrm{H}_{3} \mathrm{PO}_{3}$. For the direct codeposition mechanism of $\mathrm{Ni}-\mathrm{P}$ deposit, $\mathrm{H}_{3} \mathrm{PO}_{3}$ is directly reduced to element phosphorus (Reaction 4)

$$
\begin{gathered}
\mathrm{Ni}^{2+}+2 \mathrm{e}^{-} \rightarrow \mathrm{Ni} \\
\mathrm{H}^{+}+\mathrm{e}^{-} \rightarrow \mathrm{H}_{\mathrm{ads}} \\
\mathrm{H}_{\mathrm{ads}}+\mathrm{H}_{\mathrm{ads}} \rightarrow \mathrm{H}_{2}
\end{gathered}
$$

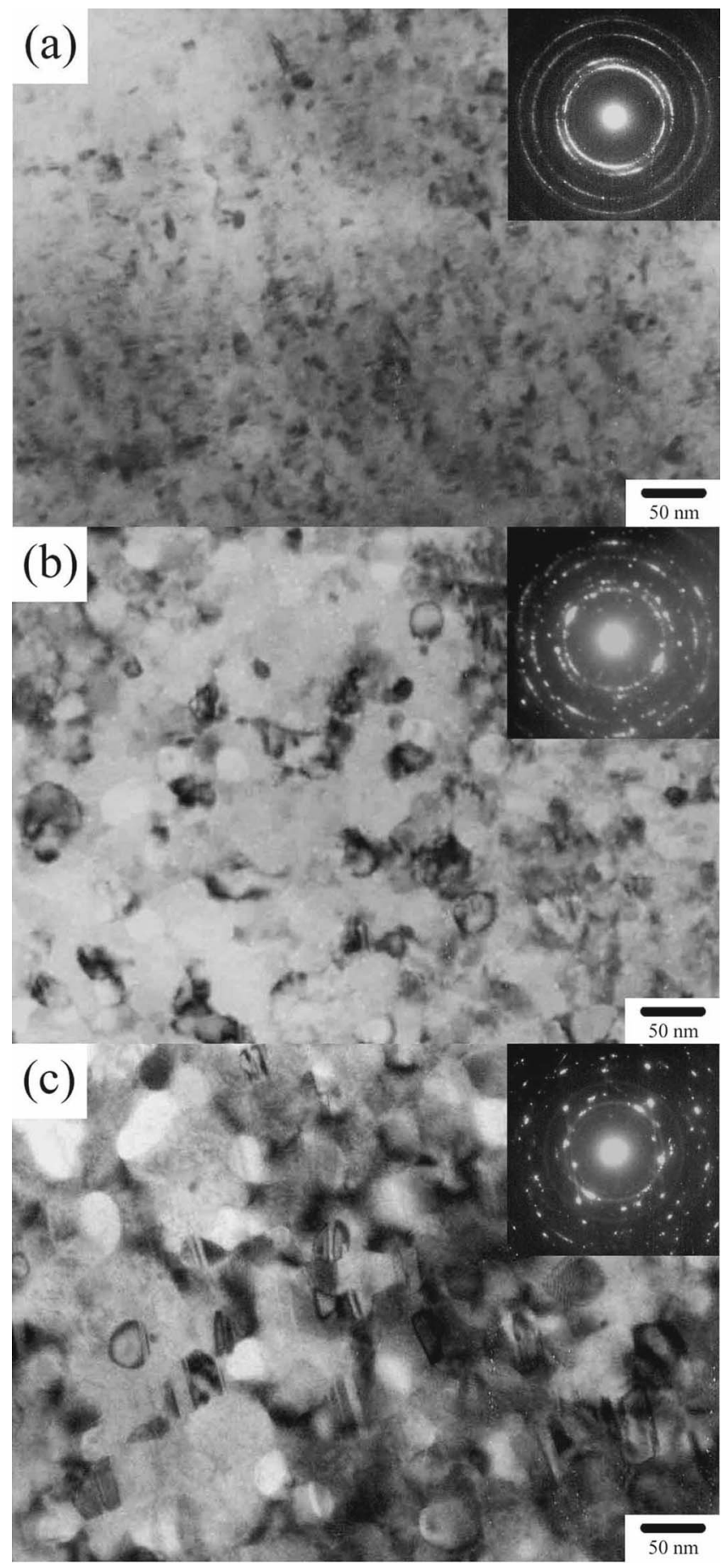

Figure 4. Cross-sectional TEM micrographs and SAED patterns of the deposits plated using the current with $I_{\mathrm{p}}=80 \mathrm{~mA} \mathrm{~cm}^{-2}$ and (a) $f=10 \mathrm{~Hz}$ and $\varepsilon=0.5$; (b) $f=10 \mathrm{~Hz}$ and $\varepsilon=0.1$; and (c) $f=100 \mathrm{~Hz}$ and $\varepsilon=0.1$.

$$
\mathrm{H}_{3} \mathrm{PO}_{3}+3 \mathrm{H}^{+}+3 \mathrm{e}^{-} \rightarrow \mathrm{P}+3 \mathrm{H}_{2} \mathrm{O}
$$

As for the indirect mechanism, $\mathrm{H}_{3} \mathrm{PO}_{3}$ is reduced to $\mathrm{PH}_{3}$, which in the presence of $\mathrm{Ni}^{2+}$ is oxidized to phosphorus, as shown in Reactions 5-7

$$
\begin{gathered}
6 \mathrm{H}^{+}+6 \mathrm{e}^{-} \rightarrow 6 \mathrm{H}_{\mathrm{ads}} \\
\mathrm{H}_{3} \mathrm{PO}_{3}+6 \mathrm{H}_{\mathrm{ads}} \rightarrow \mathrm{PH}_{3}+3 \mathrm{H}_{2} \mathrm{O}
\end{gathered}
$$




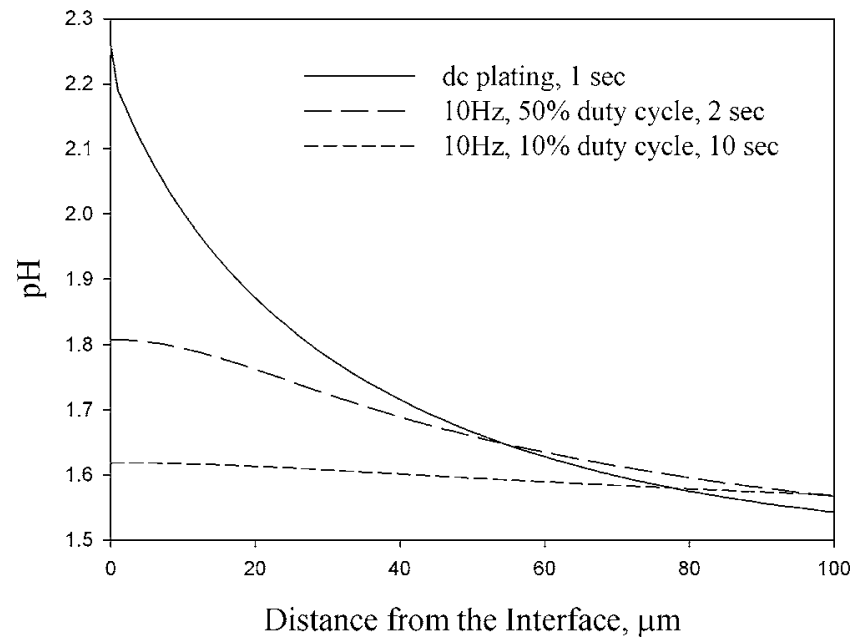

Figure 5. Simulated $\mathrm{pH}$ distributions near the plating surface for different applied waveforms with the same total supplied charge.

$$
2 \mathrm{PH}_{3}+3 \mathrm{Ni}^{2+} \rightarrow 3 \mathrm{Ni}+2 \mathrm{P}+6 \mathrm{H}^{+}
$$

According to Reactions 4-7, it is apparent that $\mathrm{H}^{+}$on the surface of the growing deposit is necessary for the codepositon of phosphorus for both direct and indirect mechanisms. For example, more $\mathrm{H}^{+}$ adsorbed on the surface promotes the reduction of $\mathrm{H}_{3} \mathrm{PO}_{3}$ to phosphorus via Reaction 4. More adsorbed $\mathrm{H}^{+}$also enhances the coverage of $\mathrm{H}_{\text {ads }}$ (Reaction 5), which, in turn, in the presence of sufficient $\mathrm{H}_{3} \mathrm{PO}_{3}$ results in more $\mathrm{PH}_{3}$, and hence more phosphorus via Reaction 7. The current efficiency can be reduced if $\mathrm{H}_{\text {ads }}$ combine together to form hydrogen bubbles (Reaction 3). Therefore, it can be expected that surface $\mathrm{H}^{+}$concentration on the growing deposit affects both the deposit phosphorus content and current efficiency.

The $\mathrm{pH}$ variation ahead of the surface of the growing deposit is related to the reduction of proton or water. For example, when the current efficiency associated with Ni-P electroplating was low, the vigorous hydrogen evolution was observed. This hydrogen evolution prevails from reduction of water, especially when protons on the surface are depleted by the cathodic charge imposed continuously during dc electroplating. ${ }^{13}$ Both proton discharge and reduction of water lead to an increase in surface $\mathrm{pH}$. As a result, a variation in the proton concentration will occur ahead of the deposit surface. Because the coverage of $\mathrm{H}_{\mathrm{ads}}$ on the surface of the growing deposit strongly depends on surface $\mathrm{pH}$, it is of immense importance to understand the effect of current waveforms on the proton concentration profile ahead of the deposit surface.

Assuming the charge that does not contribute to the growth of the deposit is consumed on proton reduction, the flux for the disappearance of proton on the surface can be expressed as

$$
J_{R}(t)=I(t)(1-\eta) \times\left(1.036 \times 10^{-4}\right)
$$

where $J_{R}$ is the reaction flux $\left(\mathrm{mole} / \mathrm{m}^{2} \mathrm{~s}\right), I$ the current density $\left(\mathrm{mA} / \mathrm{cm}^{2}\right), \eta$ the current efficiency, and $1.036 \times 10^{-4}$ is the conversion factor between the current density and the proton flux. In this study, the plating with a rectangular pulse current is considered. Hence

$$
I(t)=\left\{\begin{array}{l}
I_{\mathrm{p}}, \quad \text { as } \frac{n-1}{f} \leqslant t \leqslant \frac{n-1+\varepsilon}{f} \\
0, \quad \text { as } \frac{n-1+\varepsilon}{f}<t<\frac{n}{f}
\end{array} \quad, \quad n=1,2,3 \ldots .\right.
$$

In the above expression, $I_{\mathrm{p}}$ denotes the current density at the time-on portion (i.e., the peak current density), $\varepsilon$ represents the duty cycle ( $\varepsilon=1$ for dc plating, and $0<\varepsilon<1$ for pulse plating), and $f$ is the

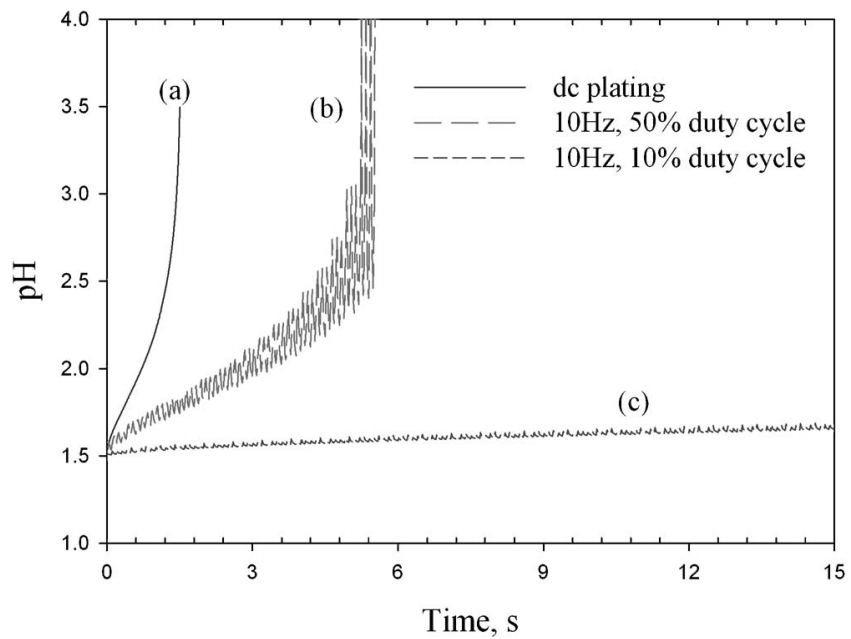

Figure 6. Simulated $\mathrm{pH}$ variation with respect to time at the plating surface $(x=0)$ under (a) dc plating; and pulse plating with (b) $f=10 \mathrm{~Hz}$ and $\varepsilon=0.5$ and (c) $f=10 \mathrm{~Hz}$ and $\varepsilon=0.1$.

frequency of the pulse current. The variation of proton concentration ahead of the surface with time is governed by Fick's second law

$$
\frac{\partial C}{\partial t}=D \frac{\partial^{2} C}{\partial x^{2}}
$$

where $C$ is the proton concentration, $D$ is the diffusivity of proton in the solution, and $x$ is the distance from the interface. If $C_{0}$ is the initial bulk concentration, the initial and boundary conditions associated with the differential equation 10 can be expressed as $\left.C(x, t)\right|_{t=0}=C_{0}$ and $\left.C(x, t)\right|_{x \rightarrow \infty}=C_{0}$ at $t>0$, respectively. Another boundary condition at the surface $x=0$ is described by Fick's first law

$$
\left.J(x, t)\right|_{x=0}=-J_{R}(t)=-D \frac{\partial C}{\partial x}
$$

With the aforementioned boundary and initial conditions, the solution of Eq. 10 can be obtained by using Laplace transform. ${ }^{30}$ The inverse Laplace transform brings the solution back to the time domain as following

$$
C(x, t)=C_{0}+\int_{0}^{t} \frac{J_{R}\left(t-t^{\prime}\right)}{\sqrt{\pi D t^{\prime}}} \exp \left(-\frac{x^{2}}{4 D t^{\prime}}\right) d t^{\prime}
$$

Herein, the convolution integral in Eq. 12 was calculated by employing numerical integration with rectangular rule.

As an example, taking the diffusivity coefficient of protons ${ }^{31}$ as $D=3.0 \times 10^{9} \mathrm{~m}^{2} / \mathrm{s}, C_{0}=10^{1.5} \mathrm{~mole} / \mathrm{m}^{3}, I_{\mathrm{P}}=80 \mathrm{~mA} / \mathrm{cm}^{2}$, and $\eta$ $=0.85$, the proton concentration profile ahead of the surface for $\mathrm{dc}$ and pulse plating can be simulated. This calculation shows that after applying the same total charge associated with dc and pulse current waveforms of different duty cycles, a more uniform concentration profile is maintained for the pulse current than for the dc current, particularly the pulse current having small duty cycles, as shown in Fig. 5. Like dc plating, surface $\mathrm{pH}$ also increases during the time on associated with a pulse current. The subsequent time off, however, allows the recovery in surface proton concentration by the bulk diffusion, giving rise to a more uniform proton concentration distribution.

Because the flux of proton diffusing to the surface is less than what has been consumed, surface $\mathrm{pH}$ generally rises with time, as shown in Fig. 6. Furthermore, surface $\mathrm{pH}$ increases at a rate significantly higher for the dc current than for the pulse current. Time off of a pulse current apparently stabilizes the surface $\mathrm{pH}$. Therefore, reducing the duty cycle would result in less $\mathrm{pH}$ increase with time 


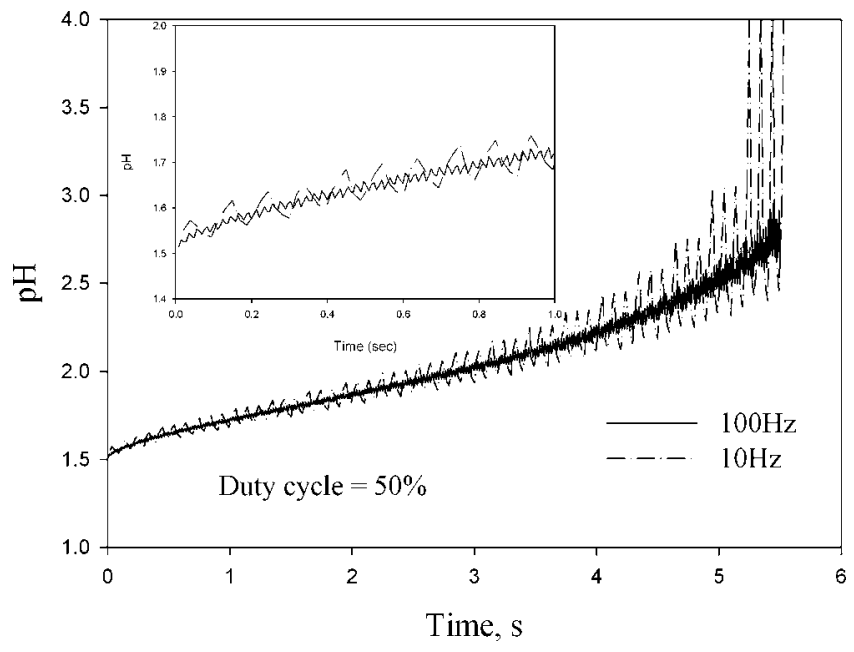

Figure 7. Simulated $\mathrm{pH}$ variation with respect to time at the plating surface $(x=0)$ under pulse plating with $50 \%$ duty cycle and different frequencies.

because low duty cycle pulse currents have longer time off, allowing larger extents of recovery in surface proton concentration, while fewer protons are discharged during time on.

Figure 7 shows the effects of pulse frequency on surface $\mathrm{pH}$ variation at a given duty cycle, i.e., $50 \%$. During a specific electroplating period, surface $\mathrm{pH}$ always oscillates about a same average value for both 10 and $100 \mathrm{~Hz}$ pulse currents. The amplitude of oscillation, however, decreases with increasing pulse frequencies, signifying a more stable surface $\mathrm{pH}$ at high frequencies.

In general, a lower and more stable surface $\mathrm{pH}$ can be achieved using the pulse current, preferentially those with low duty cycle and high frequency. Low $\mathrm{pH}$ promotes the adsorption of $\mathrm{H}^{+}$, which once reduced, enhances the coverage of $\mathrm{H}_{\text {ads }}$. Both adsorbed $\mathrm{H}^{+}$and $\mathrm{H}_{\mathrm{ads}}$ contribute to the codeposition of phosphorus in the deposit regardless of the codeposition mechanism. To further investigate the effect of $\mathrm{pH}$ on the deposit phosphorus and current efficiency, Ni-P deposition was conducted in the nickel sulfamate bath containing $10 \mathrm{~g} \mathrm{dm}^{-3} \mathrm{H}_{3} \mathrm{PO}_{3}$ solution, while its $\mathrm{pH}$ was adjusted by the addition of diluted $\mathrm{H}_{2} \mathrm{SO}_{4}$ or $\mathrm{NaOH}$. Figure 8 shows that the deposit phosphorus content decreased with increasing solution $\mathrm{pH}$. Figure 9 shows the calculated surface $\mathrm{pH}$ variation with time for the various solutions. Indeed, a sharp increase in surface $\mathrm{pH}$ is observed for the

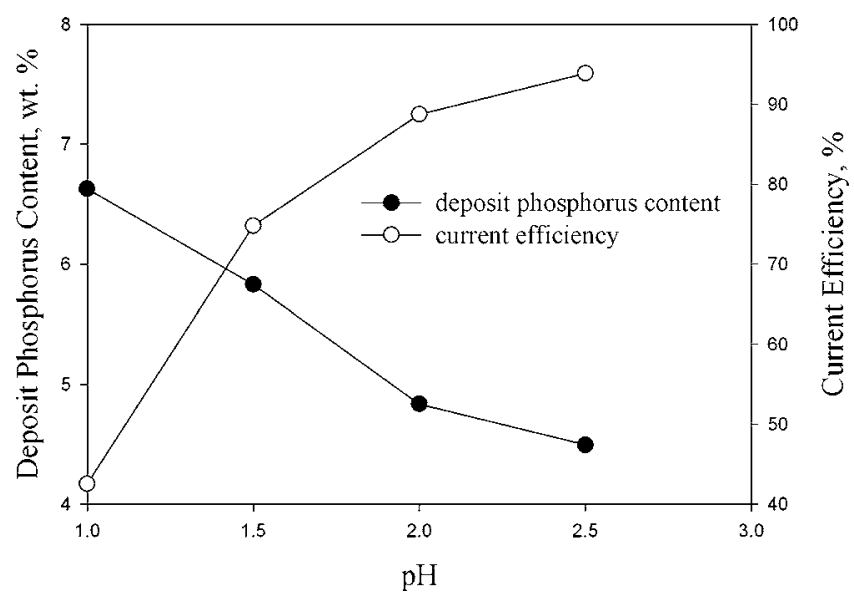

Figure 8. Effect of solution $\mathrm{pH}$ on the deposit phosphorus content and current efficiency. The concentration of $\mathrm{Ni}^{2+}$ and $\mathrm{H}_{3} \mathrm{PO}_{3}$ in the solution is 90 and $10 \mathrm{~g} \mathrm{dm}^{-3}$, respectively.

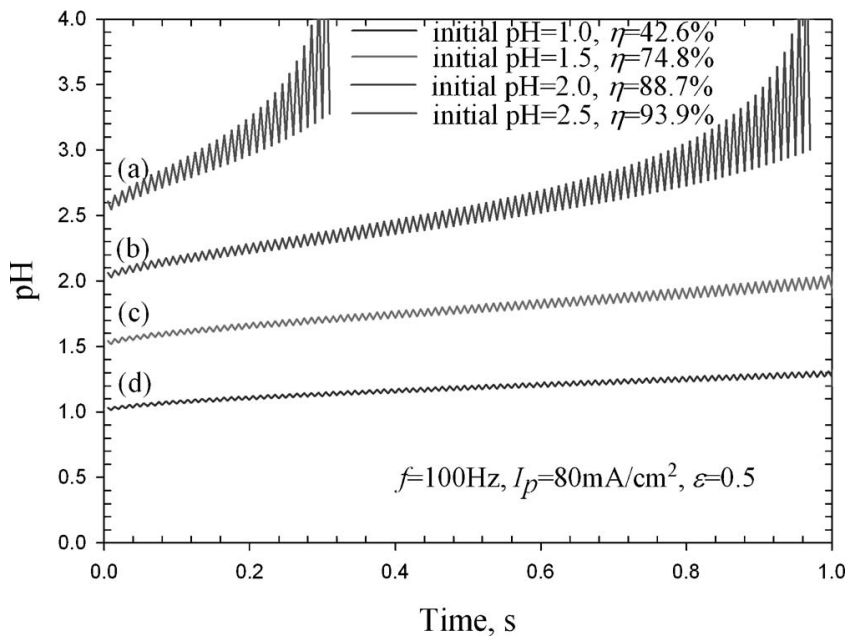

Figure 9. Simulated $\mathrm{pH}$ variation with respect to time at the plating surface $(x=0)$ in the solution with $\mathrm{pH}$ of (a) 2.5; (b) 2.0; (c) 1.5; and (d) 1.0.

solution with higher $\mathrm{pH}$, while a more stable surface $\mathrm{pH}$ is associated with the solution having lower $\mathrm{pH}$ after the elapse of the same deposition time.

Current efficiency.- Ni-P electrodeposits with various phosphorus contents can be plated by controlling the electrolyte composition and plating parameters. ${ }^{17-25}$ Especially, by varying the concentration of phosphorus oxyacid in the solution, the deposits with various phosphorus contents can be made via galvanostatic plating. ${ }^{22-25}$ However, the deposit phosphorus content increases while the current efficiency decreases with increasing phosphorus oxyacid concentration. Notably, the current efficiency of the deposits with high phosphorus content is typically less than $50 \% .^{14,22,24}$ This loss in current efficiency is generally associated with the evolution of hydrogen bubbles, i.e., under the condition that Reaction 3 prevails.

In this study, the low phosphorus content Ni-P deposits can be made using the dc current with a relatively high current efficiency, especially for the deposits whose phosphorus content is less than 2 wt $\%$ (Fig. 3). This indicates that the current efficiency of Ni-P alloys with phosphorus content less than $2 \mathrm{wt} \%$ is comparable to that of pure $\mathrm{Ni}$, which is generally plated at approximately $96 \%$ efficiency in a nickel sulfamate bath. ${ }^{27}$ In the high phosphorus ranges, the deposit is, however, plated at relatively low current efficiency using the dc current. In contrast, the high phosphorus content deposits can be plated at relatively high current efficiency for pulse plating with a specific pulse current.

Like the recovery in surface proton concentration, the time off associated with a pulse current can also contribute to release the diffusion layer associated with $\mathrm{Ni}^{2+}$ and $\mathrm{H}_{3} \mathrm{PO}_{3}$ ahead of the interface between the growing deposit and the solution. Replenishment of the reaction species at the surface certainly leads to an increase in the current efficiency, especially for the deposit with high phosphorus content. That is, $\mathrm{H}^{+}, \mathrm{Ni}^{2+}$, and $\mathrm{H}_{3} \mathrm{PO}_{3}$ are reduced during the time on of a pulse current. During the subsequent time off of the pulse current, the diffusion layer of $\mathrm{H}^{+}, \mathrm{Ni}^{2+}$, and $\mathrm{H}_{3} \mathrm{PO}_{3}$ is released; thereby, Reactions 4 and 6 can proceed to larger extents as electroplating continues. As a result, more phosphorus can be incorporated in the deposit, giving rise to high phosphorus content Ni-P deposits. Meanwhile, fewer hydrogen bubbles evolve (via Reaction 3) when more protons are consumed by Reactions 4, or 5 and 6. Furthermore, longer time off allows larger extents of Reactions 6 and 7 that are chemical reactions occurring without the cathodic charge. ${ }^{14}$ Consequently, higher current efficiency is obtained when the deposit grows via Reactions 6 and 7. 
As shown in Fig. 6, the low duty cycle pulse current provides a longer time off for keeping a lower surface $\mathrm{pH}$, and hence more absorbed $\mathrm{H}^{+}$. This $\mathrm{H}^{+}$, when reacting with $\mathrm{H}_{3} \mathrm{PO}_{3}$ in the presence of abundant absorbed $\mathrm{H}_{3} \mathrm{PO}_{3}$ and $\mathrm{Ni}^{2+}$, results in the deposit containing more phosphorus, and meanwhile avoids the loss of current efficiency by the evolution of hydrogen bubbles. Longer time off also allows a more extensive reaction of Reactions 6 and 7 in the presence of abundant $\mathrm{H}_{\mathrm{ads}}$. As a result, the low duty cycle pulse current can plate Ni-P deposit at high current efficiency.

When deposition is performed using the same pulse current in the solutions containing the same $\mathrm{Ni}^{2+}$ and $\mathrm{H}_{3} \mathrm{PO}_{3}$, but different $\mathrm{pH}$, the deposit phosphorus content decreases while the current efficiency increases with increasing $\mathrm{pH}$ (Fig. 8). Consequently, simply modifying the solution $\mathrm{pH}$ cannot plate the high phosphorus content $\mathrm{Ni}-\mathrm{P}$ deposits with high current efficiency. This indicates that for an identical surface coverage of $\mathrm{Ni}^{2+}$ and $\mathrm{H}_{3} \mathrm{PO}_{3}$, decreasing solution $\mathrm{pH}$ reduces the current efficiency. This is because decreasing solution $\mathrm{pH}$ promotes the evolution of hydrogen bubbles in the solution whose $\mathrm{Ni}^{2+}$ and $\mathrm{H}_{3} \mathrm{PO}_{3}$ concentrations are fixed. Therefore, more stable and lower surface $\mathrm{pH}$ together with less concentration polarization of $\mathrm{Ni}^{2+}$ and $\mathrm{H}_{3} \mathrm{PO}_{3}$ can be beneficial in producing high phosphorus content $\mathrm{Ni}-\mathrm{P}$ deposits with high current efficiency. This can be achieved via pulse plating, preferentially using the pulse current with low duty cycle and high frequency.

\section{Conclusions}

This study demonstrates that in the nickel sulfamate solution containing $\mathrm{H}_{3} \mathrm{PO}_{3}$, both the deposit phosphorus and current efficiency can be enhanced by replacing the dc current with the pulse current. This enhancement becomes more pronounced as the duty cycle is reduced, while it is less dependent on the pulse frequency. Employing the 0.1 duty cycle current having frequencies exceeding $100 \mathrm{~Hz}$, the deposit with $14 \mathrm{wt} \%$ phosphorus can be plated at an efficiency of around $80 \%$. Unlike the dc-plated Ni-P deposit that might become amorphous when its phosphorus content exceeds a critical value, the pulse-plated deposit with $14 \mathrm{wt} \%$ phosphorus still consists of equiaxed crystalline grains. Reducing the duty cycle seems to promote the deposit composed of larger grains. Finally, the time off associated with the pulse current leads to the replenishment in protons, $\mathrm{Ni}^{2+}$, and $\mathrm{H}_{3} \mathrm{PO}_{3}$ at the deposit/solution interface. In the presence of abundant $\mathrm{Ni}^{2+}$ and $\mathrm{H}_{3} \mathrm{PO}_{3}$, absorbed protons on the surface of the growing deposit promoted the codeposition of phosphorus in the deposits, and reduced the loss of current efficiency associated with the evolution of hydrogen bubbles. The deposit containing more phosphorus can therefore be plated using the pulse current, while maintaining a relatively high current efficiency.

\section{Acknowledgments}

This research was supported by the National Science Council, Republic of China, under grant no. 912216E002040. L. C. Wang, National Sun Yat-sen University, is recognized for her assistance with the TEM work. This study made use of the Electron Probe Micro Analyzer and Electron Microscopes of National Taiwan University and Electron Microscopes of National Sun Yat-sen University, supported by the National Science Council, Republic of China.

National Taiwan University assisted in meeting the publication costs of this article.

\section{References}

1. M. Ratzker, D. S. Lashmore, and K. W. Pratt, Plat. Surf. Finish., 73, 74 (1986).

2. R. Weil, J. H. Lee, and K. Parker, Plat. Surf. Finish., 137, 76 (1989).

3. C. J. Chen and K. L. Lin, Thin Solid Films, 370, 106 (2000).

4. B. P. Daly and F. J. Barry, Int. Mater. Rev., 48, 326 (2003).

5. C. C. Hu and A. Bai, J. Appl. Electrochem., 31, 565 (2001)

6. C. C. Hu and A. Bai, Mater. Chem. Phys., 77, 215 (2003).

7. I. Paseka, Electrochim. Acta, 40, 1633 (1995).

8. I. Paseka, Electrochim. Acta, 47, 921 (2001).

9. T. Burchardt, V. Hansen, and T. Valand, Electrochim. Acta, 46, 2761 (2001).

10. R. K. Shervedani and A. Lasia, J. Electrochem. Soc., 144, 511 (1997).

11. A. Brenner, Electrodeposition of Alloys, Vol. II, Academic Press, New York (1963).

12. T. Morikawa, T. Nakade, M. Yokoi, Y. Fukumoto, and C. Iwakura, Electrochim. Acta, 42, 115 (1997).

13. J. L. Carbajal and R. E. White, J. Electrochem. Soc., 135, 2952 (1988).

14. R. L. Zeller III and U. Landau, J. Electrochem. Soc., 139, 3464 (1992).

15. T. M. Harris and Q. D. Dang, J. Electrochem. Soc., 140, 81 (1993).

16. Y. Zeng and S. Zhou, J. Electroanal. Chem., 469, 79 (1999).

17. M. Saitou, Y. Okudaira, and W. Oshikawa, J. Electrochem. Soc., 150, C140 (2003).

18. E. Bredael, B. Blanpain, J. P. Celis, and J. R. Roos, J. Electrochem. Soc., 141, 294 (1994).

19. E. Vafaei-Makhsoos, E. L. Thomas, and L. E. Toth, Metall. Trans. A, 9, 1449 (1978).

20. K. Shimizu, G. E. Thompson, G. C. Wood, and K. Kobayashi, Philos. Mag. Lett., 61, 43 (1990).

21. C. C. Hu and A. Bai, Surf. Coat. Technol., 137, 181 (2001).

22. C. S. Lin, C. Y. Lee, F. G. Chen, and W. C. Li, J. Electrochem. Soc., 152, C370 (2005).

23. H. D. Park, D. Chang, K. H. Lee, and S. G. Kang, Plat. Surf. Finish., 88, 64 (2001).

24. G. McMahon and U. Erb, J. Mater. Sci. Lett., 8, 865 (1989).

25. R. Narayan and M. N. Mungole, Surf. Technol., 24, 233 (1985).

26. R. D. Fisher, J. Electrochem. Soc., 109, 479 (1962).

27. D. Baudrand, Met. Finish., 94, 15 (1996).

28. G. A. DiBari, Nickel Plating, ASM Materials Handbook, Vol. 5, Metals Park, OH (1994).

29. D. S. Lashmore and J. F. Weinroth, Plat. Surf. Finish., 69, 72 (1982).

30. J. O'M. Bockris and A. K. N. Reddy, Modern Electrochemistry, 1st ed., p. 312, Plenum Press, New York (1973).

31. C. K. Dyer and R. S. Alwitt, J. Electrochem. Soc., 128, 300 (1981). 